\title{
Effect of Natural Pozzolan and Calcined Paper Sludge as Pozzolanic Additions on the Physicals and Mechanicals Properties of Heat Treated Self-Compacting Mortars
}

\author{
Ghernouti Y*, Safi B, Rabehi B
}

\begin{abstract}
Research Unit: Materials, Process and Environment, university M'hamed Bougara of Boumerdes. Algeria
* Corresponding Author: y_ghernouti@yahoo.fr
\end{abstract}

Received: 26-01-2019

Accepted: 16-03-2019

\begin{abstract}
The aim of this research work was to investigate the effect of thermal treatment on strength development of self-compacting mortars (SCMs) based on two pouzolanic materials: Natural Pozzolan and calcined paper waste sludge, were used in the binders of SCMs. To evaluate the effect of heat treatment, a serial of the specimens were exposed to room temperature and another serial were exposed to heating regime (at temperature $60^{\circ} \mathrm{C}$ for a period of $14 \mathrm{~h}$ ). The fresh and hardened properties of all mortars were evaluated. the obtained result show that the mechanical strength at 14 days of all mortar treated are almost similar or sometimes better to those not treated mortars tested at 28 days, which reduces the curing time for precast elements.
\end{abstract}

Key words: Heat treatment, self-compacting mortars, pozolanic materials, calcined paper sludge.

\section{Introduction}

Presently various types of by-product materials, such as fly ash, silica fume, rice husk ash, and others have been widely used as pozzolanic materials in concrete. Their utilization not only improves concrete properties, but also preserves the environment. Fly ash (FA), and silica fume (SF) are among the most effective mineral additives used in cement or concrete because of their cementitious or pozzolanic properties (Barnett et al., 2004; ACI 233R-03, 2003; Bijen, 1996; Escalante-Garcia \& Sharp, 2001). However, they exist other industrial by-products. Recently, it was shown that the calcined silt of dam has a pozzolanic potential which gives it be used as additive. Safi et al., $(2011 ; 2012)$ showed that the introduction of $10 \%$ calcined silt (CS) of selfcompacting mortars with of ground granulated blast-furnace slag (GGBS) (30\%) has a positive effect on the rheological behavior and the development of strength. Based on the experimental work conducted by Ahmadi and Al-Khaja (2001), it can be concluded that the sludge waste generated from the paper manufacturing industry can be successfully utilized as a replacement for mineral fillers in concrete mixes for non-structural masonry construction.

Banfill and Frias (2007), studied the effects of calcined paper sludge as an alternative source of metakaolinon on the rheology and conduction calorimetry of cement pastes and compared to the effects of commercial metakaolin. The effects are similar and the results show that calcined paper sludge has the potential to be used as a supplementary cementitious material. Frías et al., (2008), in their study shows the effect of calcination clay wastes from an art paper sludge for the use as supplementary cementing materials in blended cements.

The starting clay sludge was calcined at 600,650 and $700{ }^{\circ} \mathrm{C}$ between 2 and $5 \mathrm{~h}$, kaolinite was transformed into amorphous metakaolinite. The study reveals that calcination at $650{ }^{\circ} \mathrm{C}$ for $2 \mathrm{~h}$ is recommended to obtain a good supplementary cementing material for manufacture of blended cements. Lin et al., (2010), investigate the pozzolanic reactions and strength properties of waste brick-blended cements (WBBC) in relation to various replacement ratios $(0-50 \%)$. The experimental results indicate that $10,20,30,40$ and $50 \%$ of cement can be replaced by waste 
brick, which causes the initial and final setting times to increase. Compressive strength development was slower in waste brick-blended cement (WBBC) pastes in the early ages; however, strength at the later ages increased significantly. Also, the brick waste (GWB) was the subject of several studies. The results obtained by Naceri, A., \& Hamina (2009), show that the addition of artificial pozzolan improves the setting times of the cement and the mechanical characteristics of mortar. In their work, a substitution of cement by $10 \%$ of waste brick increased mechanical strengths of mortar.

In the manufacturing field of the precast elements, companies always tried to reduce the time of preparing these elements while maintaining the quality of concrete. So, to ensure a gain of time, and significantly reducing the setting time of concrete, the parboiling (drying) process is often used for this. Due to high demand production of construction elements, the concrete industry has often resorted to use of temperature (Erdoğdu \& Kurbetci, 1998; Neville, 2000). Several methods are developed and applied in order to have a short period of realization and a sufficient resistance levels. A rise in temperature greatly accelerates the cement hydration reactions and affects advantageously the short term resistance. It also reduces the dormant period of hydrates and the overall structure of the hydrated cement paste is running at an advanced time. Indeed, an initial rapid rate of hydration due to higher temperatures causes a no uniform distribution of hydrated products (Verbeck, 1968; Kjellsen, 1996). In the construction of large structural concrete elements where heat dissipation is slow, there can be a significant rise in temperature within the first few days after casting due to the exothermic.

The main objective of this investigation is to valorise two various pouzolanic materials: natural pozzolan (NP) and calcined paper waste sludge (CPS) in the formulation of self-compacting mortars (SCMs) in order to investigate the effect of the drying temperature on the strength development of self-compacting mortars (SCM) heat-treated at $60^{\circ} \mathrm{C}$ for 14 hours for every age. The results of these tests were compared with those obtained at $20^{\circ} \mathrm{C}$ (room temperature).

\section{Experimental investigations}

\subsection{Materials used}

The cement used in this work is ordinary Portland cement (PC) equivalent to CEM II 32.5R Type. Natural Pozzolan (NP) and a metakaolin as calcined paper sludge (CPS) at $750^{\circ} \mathrm{C}$ for 5 hours obtained from a paper manufacturing industry are used as cementitious additions with particles sizes less than $80 \mu \mathrm{m}$. The chemical compositions of all cementitious materials and mineralogical composition of cement are shown in table 1 . Natural ground sand of $3 \mathrm{~mm}$ maximum particle size was used as fine aggregate. The sand has a specific gravity of $2.65 \mathrm{~g} / \mathrm{cm}^{3}$, a fineness modulus of 2.1 and its water absorption value is $5.1 \%$. A polycarboxylate-based superplasticizer named "Viscocrete tempo 12" was used to achieve the required workability of the (SCMs) mixes.

Table 1. Chemical compositions of cementitious materials and mineralogical composition of Portland cement

\begin{tabular}{|c|c|c|c|}
\hline & Portland cement (PC) & Natural pozzolan (NP) & Calcined paper sludge (CPS) \\
\hline \hline $\mathrm{SiO}_{2}$ & 21.1 & 32.4 & 21.7 \\
\hline $\mathrm{Al}_{2} \mathrm{O}_{3}$ & 4.2 & 11 & 12.6 \\
\hline $\mathrm{Fe}_{2} \mathrm{O}_{3}$ & 5.3 & 7 & 4 \\
\hline $\mathrm{CaO}$ & 61.8 & 16.6 & 22.8 \\
\hline $\mathrm{MgO}$ & 2.3 & 5.3 & 4.3 \\
\hline $\mathrm{SO}_{3}$ & 2.0 & 0.8 & 1.2 \\
\hline $\mathrm{K}_{2} \mathrm{O}+\mathrm{Na}_{2} \mathrm{O}$ & 0.6 & 4.6 & 1.3 \\
\hline $\mathrm{C}_{3} \mathrm{~S}$ & 58 & - & - \\
\hline $\mathrm{C}_{2} \mathrm{~S}$ & 18 & - & - \\
\hline $\mathrm{C}_{3} \mathrm{~A}$ & 06 & - & - \\
\hline $\mathrm{C}_{4} \mathrm{AF}$ & 13 & - & - \\
\hline
\end{tabular}




\section{Preparation of metakaolin}

After drying in an oven at $105^{\circ} \mathrm{C}$, the paper sludge (PS) was crushed and sieved through dry. The calcination temperature is in the range of $750^{\circ} \mathrm{C}$ for 5 hours. The the product obtained (calcined clay) was kept away from air and humidity. Particles passing $80 \mu \mathrm{m}$ and represent more than $95 \%$ is recovered for later use in the preparation of SCMs.

\subsection{Mixture proportions and preparation}

The self-compacting mortars (SCMs) were established made using the design method of concrete equivalent mortar (CEM) developed by Schwartzentruber \& Catherine (2000). The comparative study of (SCM) without addition and (SCMs) containing pouzzolanic materials was carried. Three compositions of SCMs mixes were prepared, a reference self-compacting mortars (SCM) without addition and two (SCMs) containing pouzzolanic materials as an additions. For all the mixtures, the total amounts of cement, sand, water and superplasticizer were all kept constant, there are in the order of $558 \mathrm{~kg} / \mathrm{m}^{3}, 1349 \mathrm{~kg} / \mathrm{m}^{3}, 276 \mathrm{~kg} / \mathrm{m}^{3}$ and $9.2 \mathrm{~kg} / \mathrm{m}^{3}$ respectively. For the two compositions of SCMs mixes with addition were prepared at the water-binder ratio is keep constant $(\mathrm{w} / \mathrm{b}=0.45)$ and the addition-cement ratio is also keep constant $(\mathrm{A} / \mathrm{C}=0.10)$. The notation of the SCMs mixtures are given as follows: SCM: control mortar; SCM (NP): Mortar with natural pozzolanic, SCM (CPS): Mortar with calcined paper sludge.

\subsection{Mixing, Casting, Curing and Testing Specimens}

After mixing process SCMs, from each mortar mixture, thirty (30) specimens were cast in prismatic molds $(40 \times 40 \times 160) \mathrm{mm}^{3}$. The Samples were used for the flexural and compressive strength tests at $3,7,14,21$ and 28 days of curing. Before casting, a slump test was carried on each mortar mixture. One day after casting, fifteen (15) specimens were stored in a room temperature (under $21 \pm 1^{\circ} \mathrm{C}$ ) and fifteen other specimens were heat treated. The total time of application temperature is 18 hours. The application of temperature involves three steps: a preheating step of $2 \mathrm{~h}$, after that, maintaining a constant intermediate temperature $\left(60^{\circ} \mathrm{C}\right)$ for a period of 14 hours. The cooling is effected in the same way that the rise. It was noted that one day before each testing age, the specimens were subjected at this thermal treatment. After each treatment, a various tests and measurements were carried on mortars out in order to study physical properties (bulk density, weight loss) and mechanical properties (flexural and compressive strength), at different ages (3, 7, 14, 21 and 28 days). The mechanical strengths were determined on specimen's heat treated and another that not heat treated and that in order to evaluate the influence of heat treatment (drying temperature) and the age of samples on the mechanical characteristics of SCMs based on various pozzolanic materials.

\section{Experimental results and discussions}

\subsection{Pozzolanic reactivity of additions used}

The study of the pozzolanic reactivity of the additions used was inspired by the test Chapel (Chinjemelo \& Billong, 2004; Bénoît, 1967). This test consists to determine the difference between the initial and final concentration of lime solution. It also allows determining the rate of $\mathrm{CaO}$ fixed by the additions. The results of the pozzolanic reactivity of all additions are presented in Figure 1. The pozzolanic reactivity is indicated by the amount of $\mathrm{CaO}$ fixed by the additions. All results of the samples show a decrease of the concentration of $\mathrm{CaO}$ in the lime solution of at least 74\%. This decrease is more advanced in natural pozzolan (NP) and calcined paper sludge (CPS) is of the order of $76.3 \%$ and $74.5 \%$ respectively. The natural pozzolan is a material known by its reactivity with pozzolanic its contains amorphous silica that will react with the portlandite $\mathrm{Ca}(\mathrm{OH})_{2}$ released during the hydration of cement. 
Metakaolin obtained from paper sludge, has a pozzolanic reactivity relatively high and which has the value closest to that of natural pozzolan.

The calcination of clays at $750^{\circ} \mathrm{C}$ allows the departure of the water content (the dehydroxylation) and the formation of metakaolin (Samet et al., 2007; Michel, 1989) with an amorphous structure which makes it more reactive than the clay. This explains the strong decrease in $\mathrm{CaO}$ concentration of the solution. The heat treatment causes the transition of the crystalline phase and orderly (kaolinite) in a disordered phase (metakaolin) by a collapse of the crystal structure. Metakaolin is considered a good synthetic pozzolans, due to its particular reaction with lime in the presence of water to form compounds of the silicate and aluminate of calcium hydrates (Wild \& Khatib, 1997; Frias etal., 2000; Poon et al., 2001).

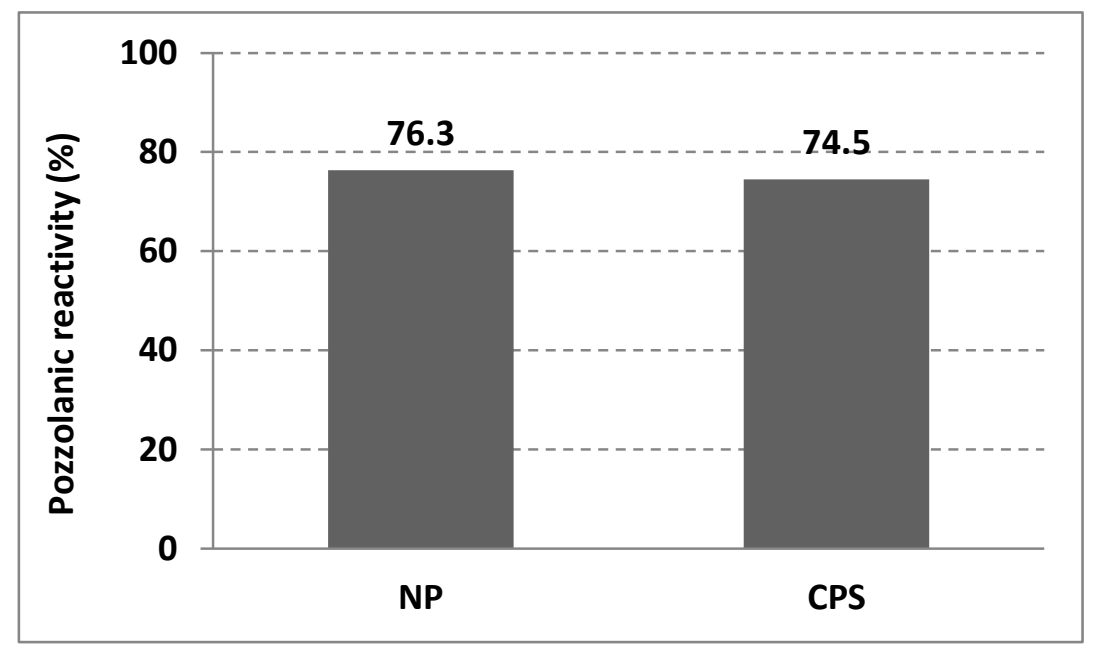

Fig. 1. Pozzolanic reactivity of all additions.

\subsection{Fresh properties}

\subsubsection{Workability}

The fresh properties of all studied mortars were evaluated by the slump test using a mini-cone. The slump value is the average diameter of spreading of mortar. The results of slump value of all SCMs mixtures are represented in the histogram of figure 2. In fluidity terms, all SCMs mixtures have a satisfactory slump flows which suitable for self-compacting concrete. The slump value is in the range of $28-32 \mathrm{~cm}$ which is a good deformability. The results indicate that the slump flows of all mixture mortars are similar. Figure 3, presents the photography of the slump flow test off all SCMs mixtures.

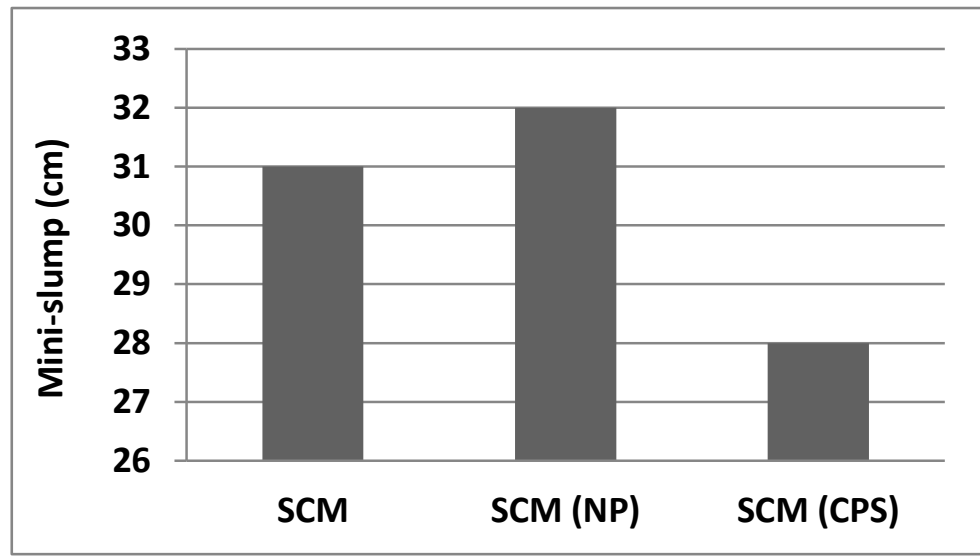

Fig. 2. Mini-slump for all SCMs mortars mixes. 

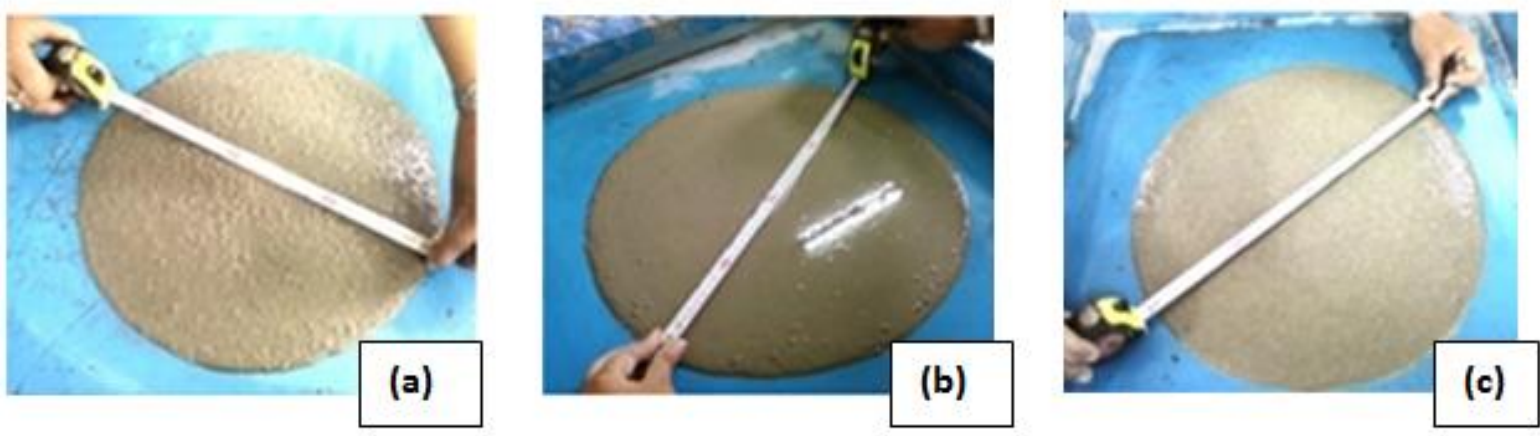

Fig. 3. Photography of Slump flow of various SCMs mortars mixes: (a) SCM, (b) SCM(NP), (c) SCM(CPS).

\subsubsection{Bulk density}

Fig 4, shows the bulk density evolution of all mortars. According these results, the recorded density is relatively high for mortars with additions compared to the control mortar (without additions). This is explained by the filling role the cementitious matrix by these additions. Given they have a high finesse and are also added as binder in material matrix, fit into the gaps, they density the mortar skeleton resulting a reduction in voids and increase in density.

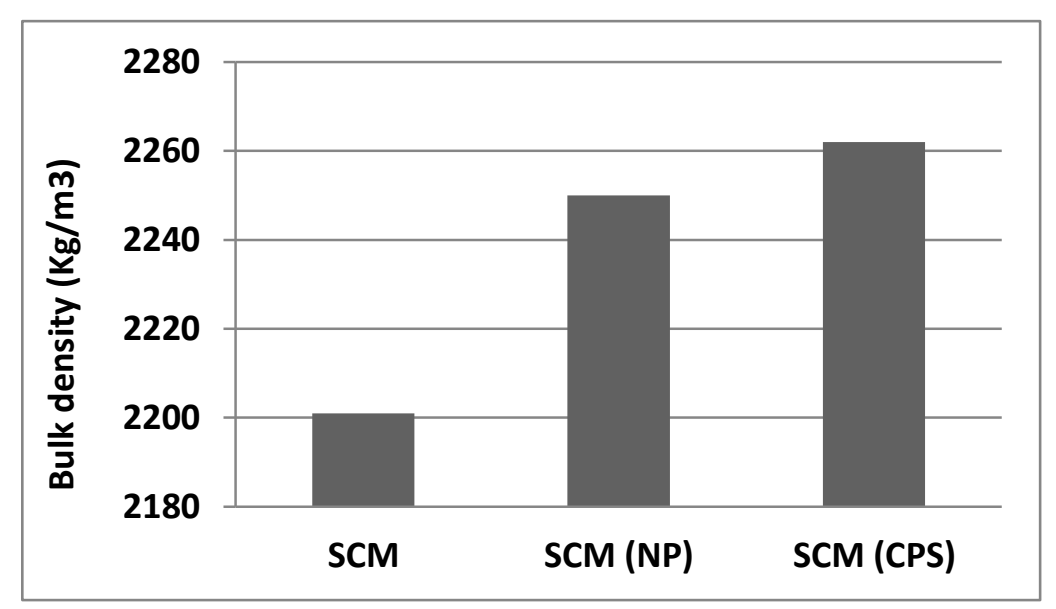

Fig. 4. Bulk density of all SCMs mortars mixes.

\subsection{Hardened properties}

\subsubsection{Flexural and compressive strength}

The mechanicals properties of the SCMs were studied by testing the $(40 \times 40 \times 160) \mathrm{mm}^{3}$ samples under 3 point flexural and uniaxial compressions, in accordance with standard NF EN196-1 (2006). Three samples were tested in flexure and the six half-samples obtained were tested in uni-axial compression on a hydraulic press with a capacity of $3000 \mathrm{KN}$. The mechanical tests for the mortars were performed at 3, 7, 14, 21 and 28 days (curing at temperature room). The results obtained of all SCMs mixtures are given in figures 5 and 6 . The figures present respectively the flexural and compressive strength of SCMs mortars with and without heat treatment. 

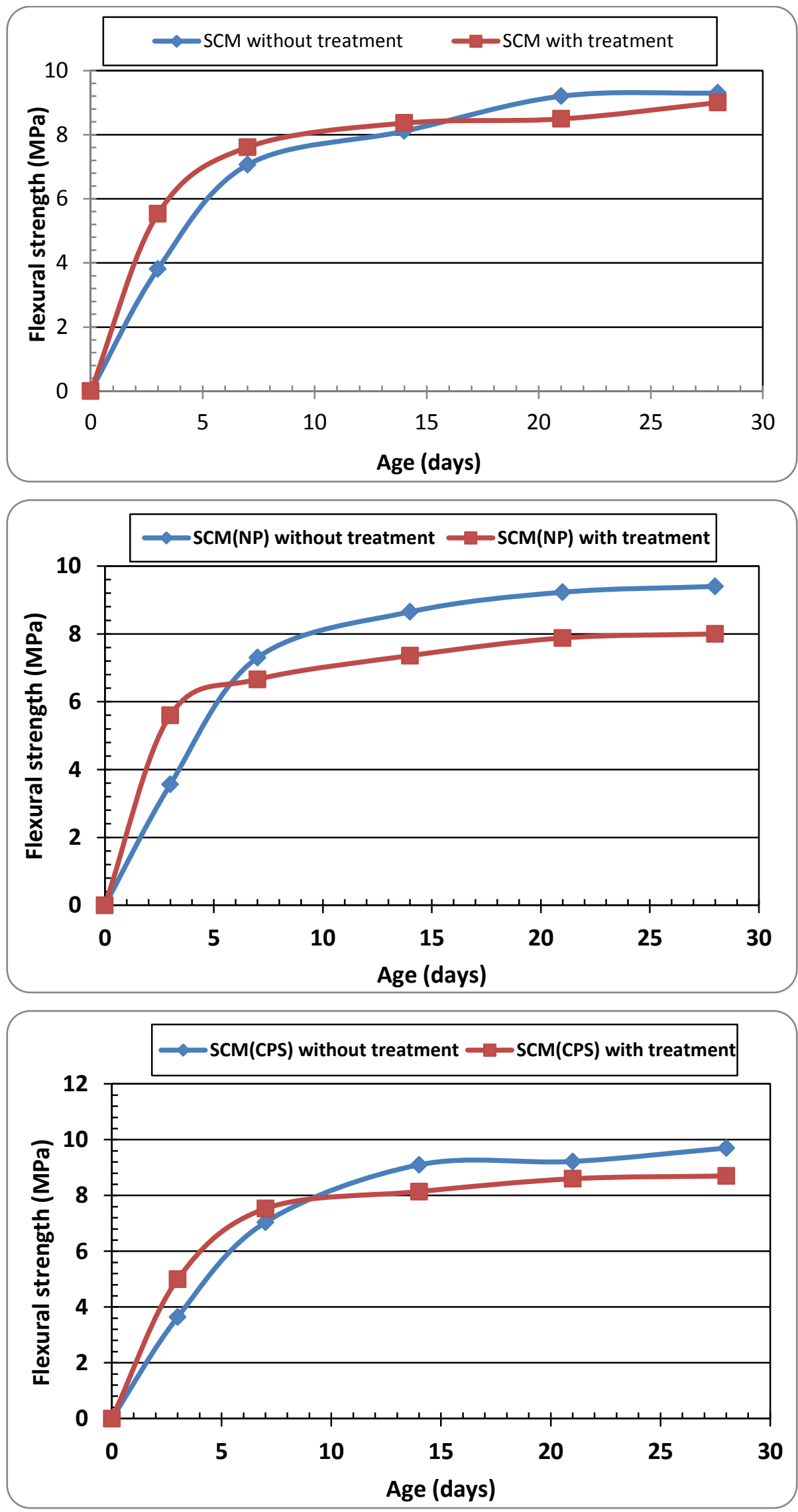

Fig. 5. Evolution of the flexural strength of all SCMs mortars with and without heat treatment. 

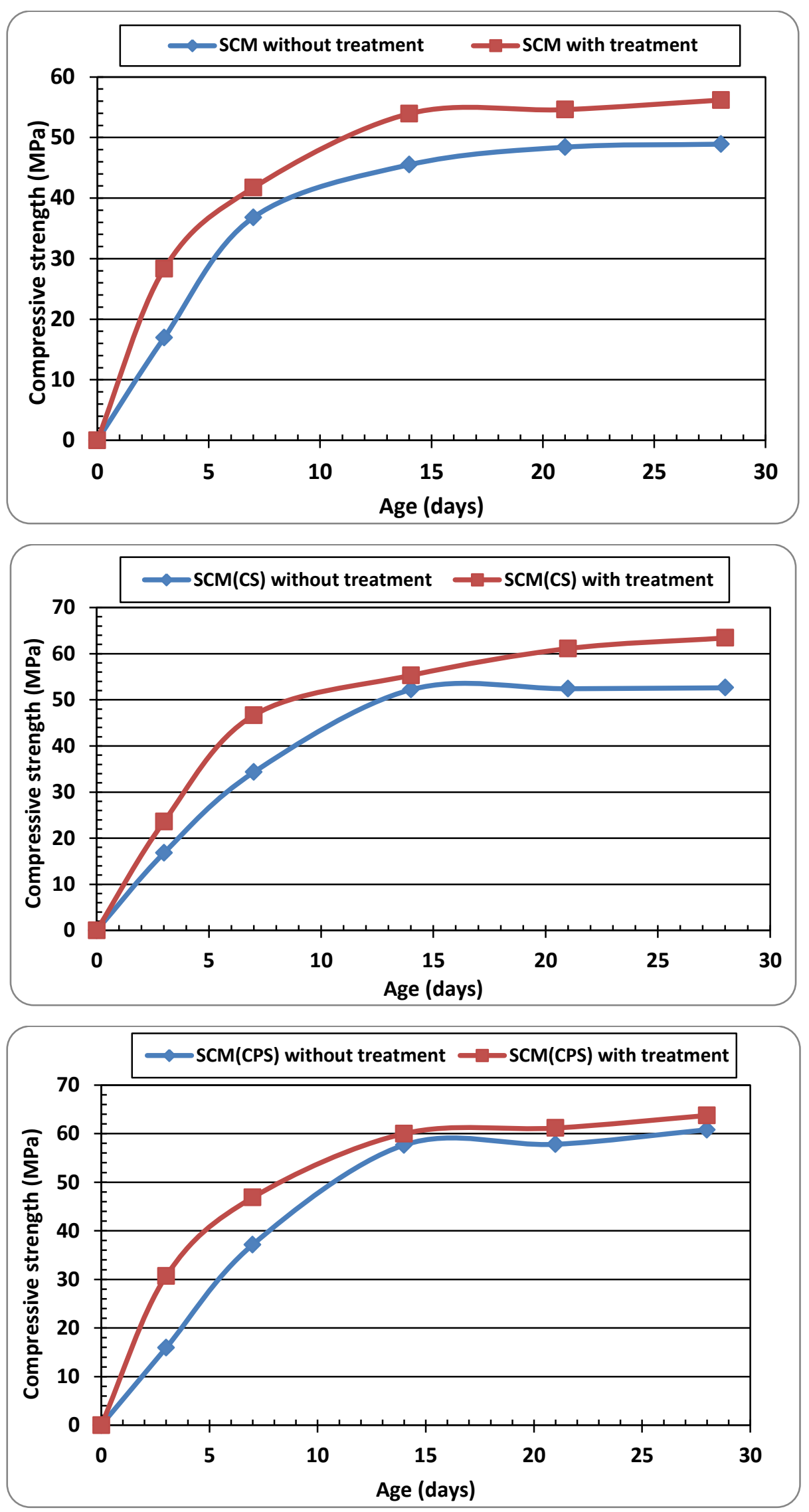

Fig. 6. Evolution of the compressive strength of all SCMs mortars with and without heat treatment. 
It is clearly that the flexural and compressive strength increases for all curing age $(3,7,14,21$ and 28 days). That is attributed to the hydration phenomenon of cement which causes the evolution of compactness with curing time. Indeed, the hydration of the cement minerals $\left(\mathrm{C}_{3} \mathrm{~S}\right.$ and $\mathrm{C}_{2} \mathrm{~S}$ ), give birth of the calcium silicate hydrate $(\mathrm{CSH})$ which increases resistance of mortar. It is noted that, at 28 days the reference mortar presents a strength value slightly low comparatively with those of the SCMs mortars with additions. This difference is due mainly to the pozzolanic property of the additions having an (totally or partially) amorphous structure which in the $\mathrm{Ca}(\mathrm{OH})_{2}$ presence released during the hydration of cement and water, gives birth new products ( $\mathrm{CSH}$ and $\mathrm{CAH}$ ), having same properties similar to those formed containing minerals of cement (Wild, 1996 ; Reinhardt \& Stegmaier, 2006).

For flexural strength of mortars having undergone heat treatment, continuous improvement was observed compared to mortars up to 14 days without treatment, or it was found the opposite effect, this can be explained by the fragility of specimens from this age processing and ripening (Figure 5), it has been proven in the work of Safi et al., (2013). The temperature has a beneficial effect on the resistance of mortars.

The results obtained show that mortars which have undergone heat treatment (figure 6), exhibit a better compressive strength as a function of age $(3,7,14,21$ and 28 days), compared to those without treatment, which is probably due the effect of temperature. An improvement in the compressive strengths at 28 days is $7 \mathrm{MPa}$ for the control mortar SCM, $2 \mathrm{MPa}$ for the SCM (NP) mortar and $3 \mathrm{MPa}$ for the SCM (CPS). According to figure 7, the compressive strength values at 14 days, obtained for all mortar compositions having undergone thermal treatment, are almost similar or sometimes better than those obtained by non-heat treated mortars at 28 days, which reduces the curing time for precast elements.

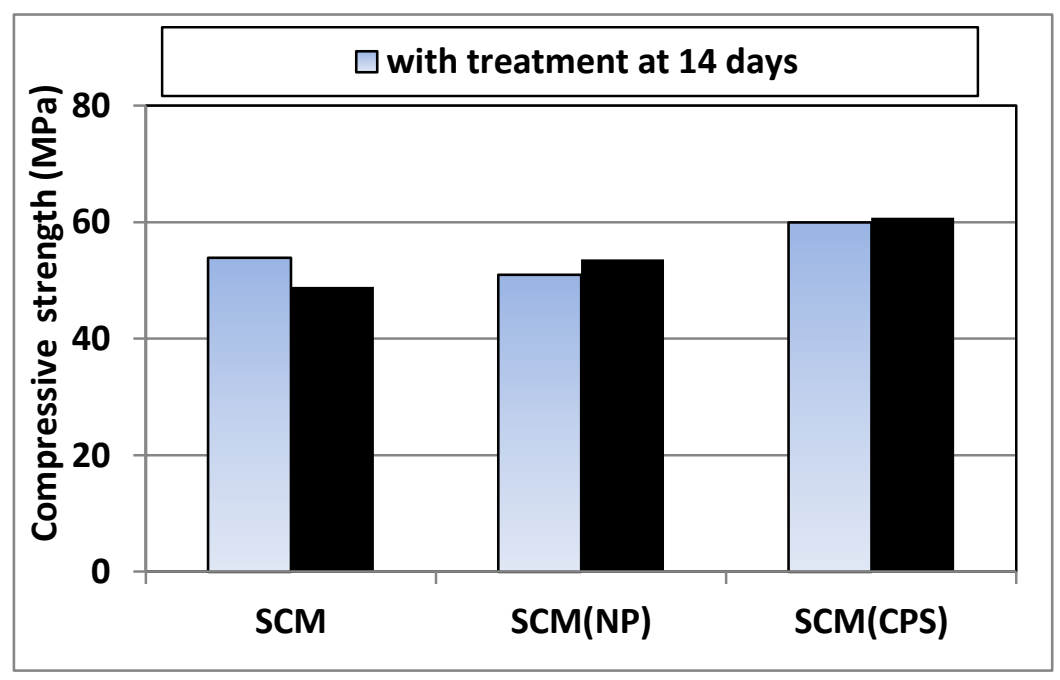

Fig. 7. Comparison of compressive strength of SCMs mortars thermally treated at 14 days and untreated at 28 days

In order to see the strength development of mortars studied under the effect of heat treatment at each curing age, Figure 8 has been established in this direction. Indeed, this figure shows the improvements in compressive strength of mortars treated (at $60^{\circ} \mathrm{C}$ ) compared to those untreated. So, it can be noted that an improvement in the compressive strengths at 28 days by the heat treatment $\left(60^{\circ} \mathrm{C}\right)$ was less significant whatever the type of additives used. However, at 3 days of curing age a significant improvement of strength for all mortars. The heat treatment improved the compressive strength of mortars, especially at young age. Indeed, at 3 days the strength gain was $67 \%$ for mortar without addition and $93 \%$ for mortar with natural pozzolan SCM (NP) or mortar with calcined paper sludge SCM (CPS). This can be explained also by 
accelerating of pozzolanic reactivity of these additions (Naturel pozzolan and calcined paper sludge).

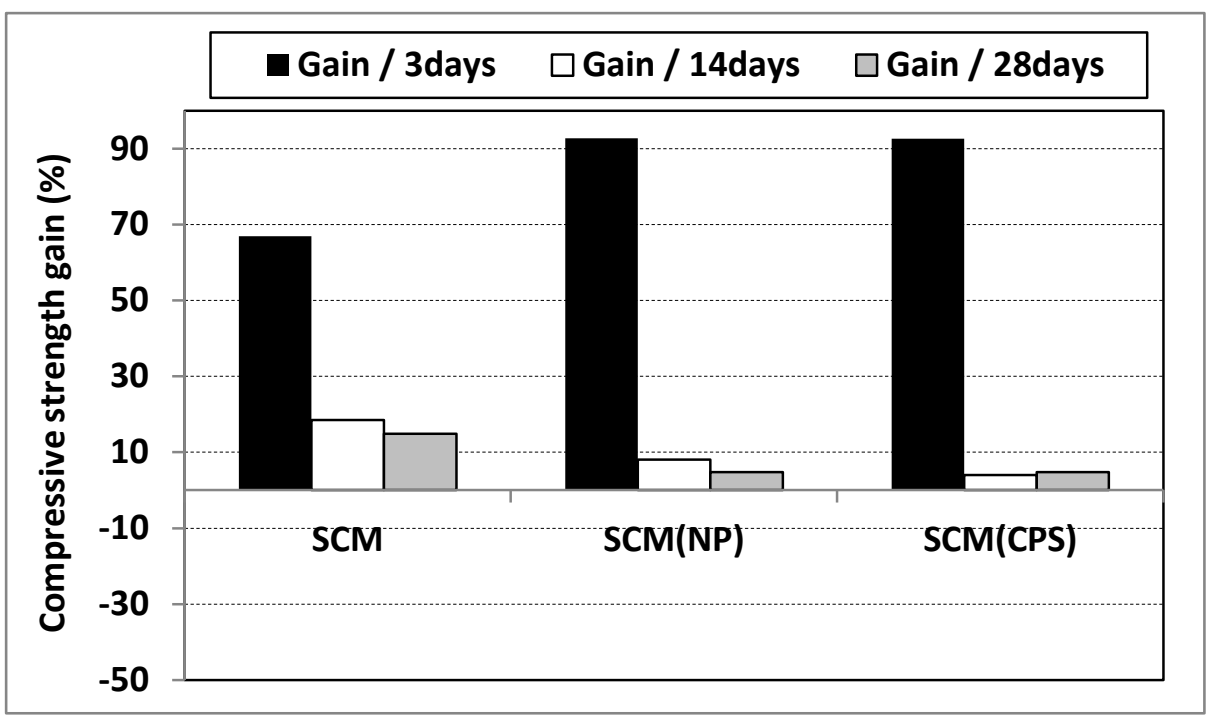

Fig. 8. Compressive strength gain of the thermally treated SCMs mortars compared to untreated mortars.

\subsubsection{Evolution of weight}

To see the chosen additions effect on the weight (gain or loss) of mortars, the mass measurements was performed. The obtained results of the weight evolution during 28 days of hardening are given in figure 9. According this figure, it was recorded that a continuous increase in the weight of different mortars during to the curing age. It can be explained by due to the cement hydration reaction at short-time which giving thus the formation of new hydrates. It is also noted that weight changes of studied mortars with additions is almost similar to the control mortar (without addition) and in sometimes is better, for example, the mortar containing calcined paper sludge SCM (CPS) has a less weight about $28 \%$ compared to the reference mortar (figure 10). This explains by the beneficial effect of the pozzolanic reaction of mineral additives (Barnett, 2004; Safi et al., 2011).

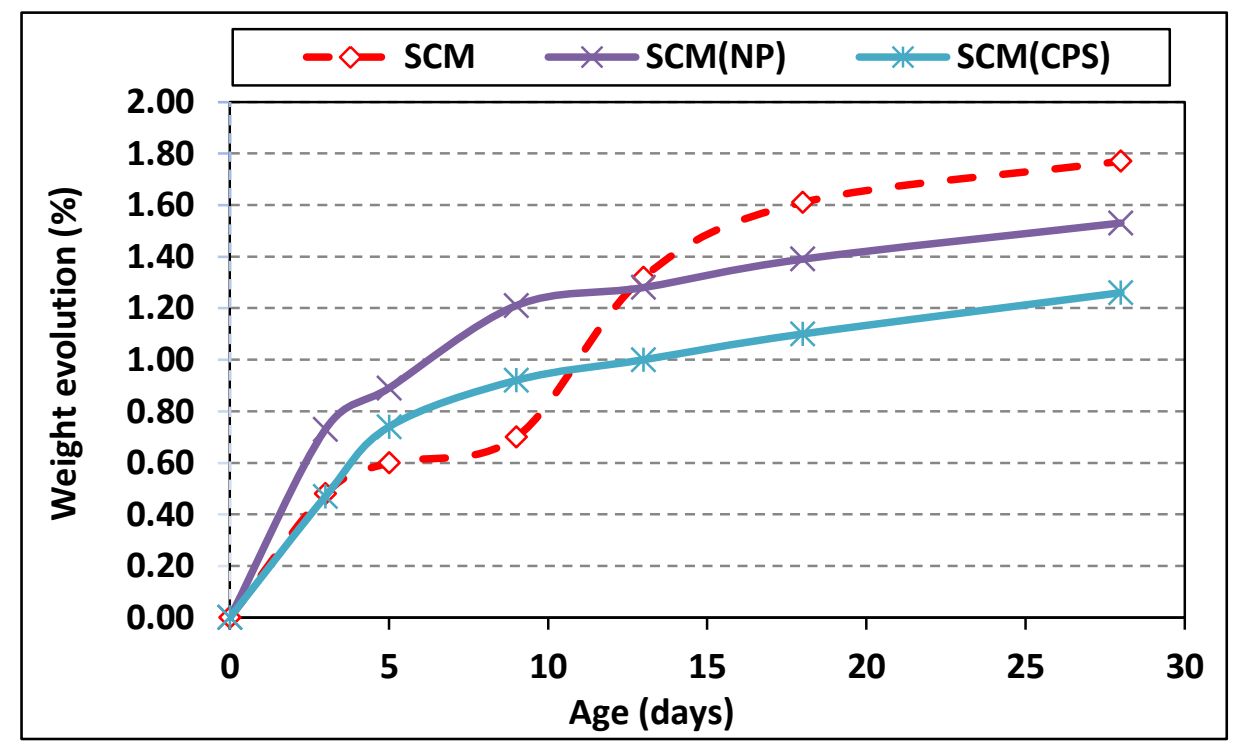

Fig. 9. Weight evolution of all SCMs mortars as function age. 


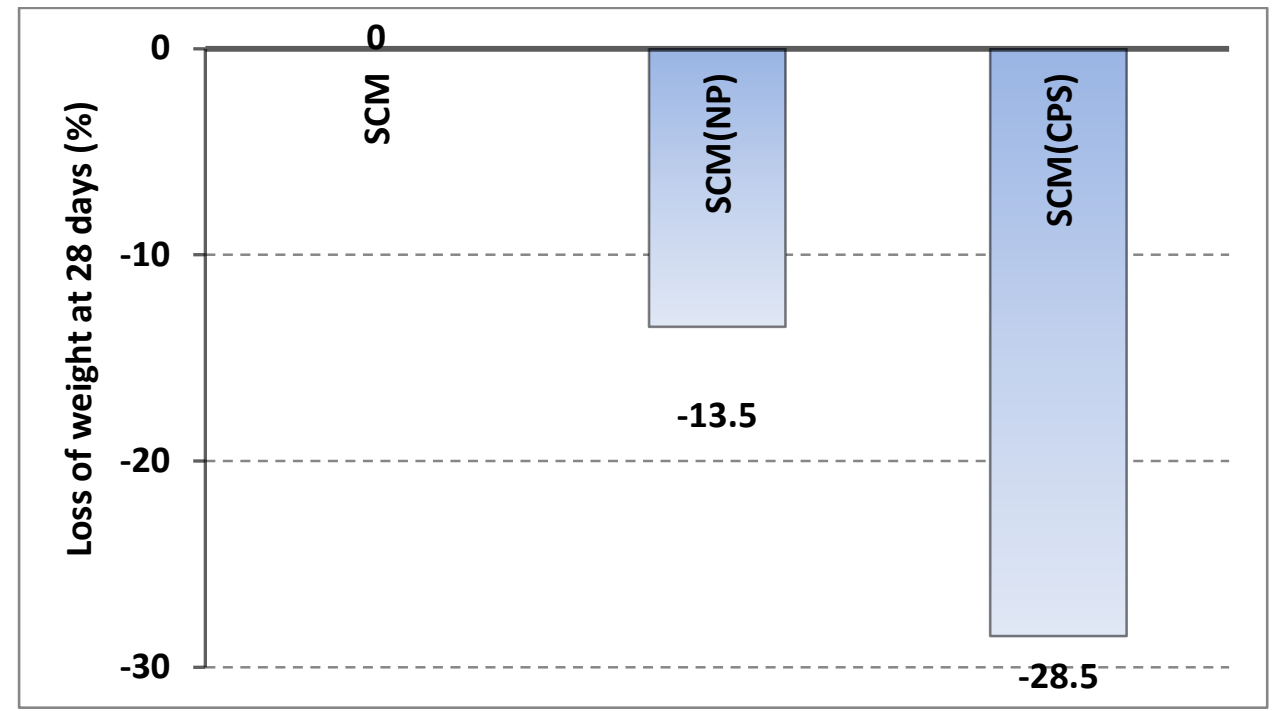

Fig. 10. Loss weight of all SCMs mortars at 28 days Compared to the reference mortar.

\section{Conclusion}

The aim of this study was the heat treatment effect on the strength development of selfcompacting mortars based on two (02) different types of mineral additions which are: Natural Pozzolan (NP) and calcined paper sludge as metakaolin. It results that:

1- The fluidity of all mortars, was acceptable for self-compacting concretes $(28 \mathrm{~cm}-32 \mathrm{~cm})$ giving a good flow stable and without vibration;

2- The weight evolution of different mortars with additions was almost similar and in sometimes better compared to the control mortar (without addition). It was reported the mortar based calcined paper sludge (CPS) has a less weight about $28 \%$ at 28 days compared to the reference mortar.

3- The mechanical strengths (compressive and flexural strength) are significantly improved in the presence of the various pozzolanic materials: natural pouzzolan, and calcined paper sludge;

4- Comparatively to age 3 days, it can be also reported that an improvement in the compressive strengths at 28 days by the heat treatment $\left(60^{\circ} \mathrm{C}\right)$ was less significant whatever the type of additives used.

5- Compared to reference mortar (without heat treatment at 28 days) significant improvements of the compressive strength of mortars studied heated thermally at age 14 days were recorded. They were sometimes similar, which is beneficial to use precast elements by mortars treated at the age of 14 days..

\section{References}

ACI 233R-03 (2003). Slag Cement in Concrete and Mortar, Report of ACI Committee 233, American Concrete Institute, Farmington Hills, Mich.

Ahmadi, B., \& Al-Khaja, W. (2001). Utilization of paper waste sludge in the building construction industry. Resources, conservation and recycling, 32(2), 105-113.

Banfill, P., \& Frias, M. (2007). Rheology and conduction calorimetry of cement modified with calcined paper sludge. Cement and concrete research, 37(2), 184-190.. 
Barnett, S. J., Soutsos, M. N., Bungey, J. H., \& Millard, S. G. (2004). Fast-track concrete construction using cement replacement materials. Special Publication, 221, 135-152.

Bénoît, O. (1967). Détermination de l'activité pouzzolanique d'une pouzzolane par voie Chimique. Bull liaison labo. P. et Ch, (26), D1-D5.

Bijen, J. M. J. M. (1996). Blast furnace slag cement for durable marine structures. Stichting BetonPrisma.

Chinjemelo, U., \& Billong, N. (2004). Activité pouzzolanique des déchets de briques et tuiles'. African Journal of Science and Technology, 5(1),92-100.

Erdoğdu, S., \& Kurbetci, S. (1998). Optimum heat treatment cycle for cements of different type and composition. Cement and concrete research, 28(11), 1595-1604.

Escalante-Garcia, J. I., \& Sharp, J. H. (2001). The microstructure and mechanical properties of blended cements hydrated at various temperatures. Cement and Concrete Research, 31(5), 695-702.

Frias, M., De Rojas, M. S., \& Cabrera, J. (2000). The effect that the pozzolanic reaction of metakaolin has on the heat evolution in metakaolin-cement mortars. Cement and concrete research, 30(2), 209-216.

Frías, M., García, R., Vigil, R., \& Ferreiro, S. (2008). Calcination of art paper sludge waste for the use as a supplementary cementing material. Applied Clay Science, 42(1-2), 189-193.

Kjellsen, K. O. (1996). Heat curing and post-heat curing regimes of high-performance concrete: influence on microstructure and CSH composition. Cement and Concrete Research, 26(2), 295-307.

Lin, K. L., Chen, B. Y., Chiou, C. S., \& Cheng, A. (2010). Waste brick's potential for use as a pozzolan in blended Portland cement. Waste Management \& Research, 28(7), 647-652.

Michel, V. (1989). La pratique des ciments, mortiers et bétons'. Edition le moniteur.

Naceri, A., \& Hamina, M. C. (2009). Use of waste brick as a partial replacement of cement in mortar. Waste management, 29(8), 2378-2384.

Neville, A. M. (2000). Propriétés des bétons. Eyrolles, Paris.

NF EN 196-1 (2006). Cement. Part 1: composition, specification and conformity criteria for common cements, AFNOR.

Poon, C. S., Lam, L., Kou, S. C., Wong, Y. L., \& Wong, R. (2001). Rate of pozzolanic reaction of metakaolin in high-performance cement pastes. Cement and Concrete Research, 31(9), 1301-1306.

Reinhardt, H. W., \& Stegmaier, M. (2006). Influence of heat curing on the pore structure and compressive strength of self-compacting concrete (SCC). Cement and Concrete Research, 36(5), 879-885.

Safi, B., Ghernouti, Y., Rabehi, B., \& Aboutaleb, D. (2013). Effect of the heat curing on strength development of self-compacting mortars containing calcined silt of dams and Ground Brick Waste. Materials Research, 16(5), 1058-1064.

Samet, B., Mnif, T., \& Chaabouni, M. (2007). Use of a kaolinitic clay as a pozzolanic material for cements: Formulation of blended cement. Cement and Concrete Composites, 29(10), 741-749.

Schwartzentruber, A., \& Catherine, C. (2000). La méthode du mortier de béton équivalent (MBE)—Un nouvel outil d'aide à la formulation des bétons adjuvantés. Materials and structures, 33(8), 475482.

Verbeck, G. J. (1968). Structures and physical properties of cement paste. In 5th International Congress on the Chemistry of Cement, 1968 (Vol. 3, pp. 1-37),

Wild, S. (1996). Observations on the use of ground waste clay brick as a cement replacement material. Building research and information, 24(1), 35-40.

Wild, S., \& Khatib, J. M. (1997). Portlandite consumption in metakaolin cement pastes and mortars. Cement and concrete research, 27(1), 137-146. 